\title{
Focal Electrical Stimulation of Major Ganglion Cell Types in the Primate Retina for the Design of Visual Prostheses
}

\author{
Lauren H. Jepson, ${ }^{1,2}$ Paweł Hottowy, ${ }^{3}$ Keith Mathieson, ${ }^{4}$ Deborah E. Gunning, ${ }^{4}$ Władysław Dąbrowski, ${ }^{3}$ Alan M. Litke, ${ }^{5}$ \\ and E. J. Chichilnisky ${ }^{1}$ \\ ${ }^{1}$ Systems Neurobiology Laboratories, Salk Institute for Biological Studies, La Jolla, California 92037, 2 Bioengineering Department, University of California, \\ San Diego, California 92093, ${ }^{3}$ AGH University of Science and Technology, Faculty of Physics and Applied Computer Science, 30-059, Krakow, Poland, \\ ${ }^{4}$ Institute of Photonics, SUPA, University of Strathclyde, Glasgow G4 0NW, United Kingdom, and ${ }^{5}$ Santa Cruz Institute for Particle Physics, University of \\ California, Santa Cruz, California 95064
}

Electrical stimulation of retinal neurons with an advanced retinal prosthesis may eventually provide high-resolution artificial vision to the blind. However, the success of future prostheses depends on the ability to activate the major parallel visual pathways of the human visual system. Electrical stimulation of the five numerically dominant retinal ganglion cell types was investigated by simultaneous stimulation and recording in isolated peripheral primate (Macaca sp.) retina using multi-electrode arrays. $\mathrm{ON}$ and $\mathrm{OFF}$ midget, $\mathrm{ON}$ and OFF parasol, and small bistratified ganglion cells could all be activated directly to fire a single spike with submillisecond latency using brief pulses of current within established safety limits. Thresholds for electrical stimulation were similar in all five cell types. In many cases, a single cell could be specifically activated without activating neighboring cells of the same type or other types. These findings support the feasibility of direct electrical stimulation of the major visual pathways at or near their native spatial and temporal resolution.

\section{Introduction}

Retinal prostheses have the potential to restore useful visual function to people blinded by diseases such as retinitis pigmentosa and age-related macular degeneration. In advanced stages of disease, photoreceptors degenerate but many other retinal neurons remain, notably a significant fraction of the retinal ganglion cells (RGCs) that normally transmit visual signals to the brain (Santos et al., 1997; Medeiros and Curcio, 2001). Thus, vision could in principle be restored in these patients by electrically stimulating the remaining RGCs with an array of electrodes, in a manner that mimics the signals that a healthy retina would transmit to the brain. Indeed, clinical trials with prototype epiretinal prostheses have shown that electrical stimulation based on signals from an external camera can induce artificial visual percepts and allow

\footnotetext{
Received Oct. 9, 2012; revised Feb. 17, 2013; accepted Feb. 22, 2013.

Author contributions: L.H.J., P.H., W.D., A.M.L., and E.J.C. designed research; L.H.J., P.H., K.M., D.E.G., and E.J.C. performed research; L.H.J. and E.J.C. analyzed data; L.H.J. and E.J.C. wrote the paper.

This work was supported by National Eye Institute Grant R01EY021271 (E.J.C.), a Sanofi-Aventis Discovery Grant (E.J.C.), the Salk Institute for Biological Studies (E.J.C., L.H.J.), the Joseph Alexander Foundation (E.J.C., L.H.J.), National Science Foundation Grant PHY-0750525 (A.M.L.), National Institutes of Health Grant 5R21EB004410 (A.M.L.), the McKnight Foundation (E.J.C., A.M.L.), Engineering and Physical Sciences Research Council (EPSRC) Grant EP/E039731/1 (D.E.G.), a Royal Society of Edinburgh fellowship (K.M.), a Research Councils UK- funded SU2P fellowship (K.M.), EPSRC Grant GR/R89189/01 (K.M.), and the Polish Ministry of Science and Higher Education and its grants for Scientific Research (W.D.). We thank Martin Greschner for help with experiments and data analysis; Matthew Grivich for software development; Clare Hulse for technical assistance; Tomasz Fiutowski, Sergei Kachiguine, Andrzej Skoczen, and Alexander Sher for technical development; Steve Barry for machining; Rich Krauzlis, John Reynolds, Mike Taffe, Ed Callaway, Tom Albright, and Howard Fox for access to primate retinas; Jeff Gauthier, Peter Li, and Greg Field for useful discussions; and Gabe Silva for support and discussions.

The authors declare no competing financial interests.

Correspondence should be addressed to Lauren H. Jepson, SNL-E, Salk Institute for Biological Studies, 10010 North Torrey Pines Road, La Jolla, CA 92037. E-mail: Ihruby@salk.edu.

DOI:10.1523/JNEUROSCI.4967-12.2013

Copyright $\odot 2013$ the authors $\quad 0270-6474 / 13 / 337194-12 \$ 15.00 / 0$
}

patients to perform simple visual tasks (for review, see Weiland et al., 2011). However, it is still unknown exactly what retinal activity is evoked by epiretinal stimulation and how this activity can be harnessed to produce high-resolution visual signals in the parallel pathways of the human visual system.

Ideally, an epiretinal prosthesis would recreate the healthy RGC response to a visual scene at the native spatial and temporal precision of RGCs. A critical first step is to understand how different types of RGCs respond to electrical stimulation. This is important because the primate retina contains multiple morphologically distinct RGC types, each of which sends distinct visual information to a distinct set of targets in the brain (for review, see Dacey, 2004; Field and Chichilnisky, 2007). To date, the only primate RGC types that have been shown to respond to epiretinal stimulation are the ON and OFF parasol cells (Sekirnjak et al., 2008), which comprise $\sim 16 \%$ of the population (for review, see Dacey, 2004). Therefore, it is unclear whether electrical stimulation can be used to create a more complete visual signal in the output of the retina. In particular, different RGC types could be differentially sensitive to electrical stimulation, a possibility that is supported by differences in the sensitivity of distinct rabbit RGC types (Fried et al., 2009), as well as differences in intrinsic electrical properties (Margolis and Detwiler, 2007; for review, see Ishida, 2003) and morphology (for review, see Masland, 2001; Dacey, 2004; Berson, 2008) between RGC types in several species. In addition to the ON and OFF parasol cells, three cell types of particular importance in the primate retina are the ON and OFF midget cells, which are responsible for high-acuity vision and make up approximately half of the total RGC population, and the small bistratified cells (SBCs), which encode blue-yellow color information. A unified understanding of the responses to electri- 
cal stimulation of all five major RGC types, which together make up roughly $75 \%$ of primate RGCs, is essential for the design of retinal prostheses capable of mediating advanced artificial vision.

We probed the response properties of the five major ganglion cell types by simultaneous electrical recording and stimulation in isolated peripheral primate retina $\left(31.4-65.9^{\circ}\right.$ temporal equivalent eccentricity) using multi-electrode arrays (Hottowy et al., 2008, 2012). The results reveal that it is possible to directly stimulate ON and OFF midget, ON and OFF parasol, and small bistratified RGCs using $\sim 15 \mu \mathrm{m}$ diameter electrodes with current pulses in a safe charge density range. RGCs from all five cell types exhibited similar sensitivity to brief current pulses, responding with a single, precisely timed spike, suggesting that the neural code of the retina can be reproduced with high fidelity. By recording simultaneously from midget and parasol cells while targeting midget cells for stimulation, we show that single-cell specificity in the highest-density cell types is achievable in many cases. Thus, in principle it is possible to safely electrically activate RGCs in the high-resolution visual pathways at their native spatial and temporal resolution.

\section{Materials and Methods}

Experimental setup. Primate retinas were isolated and mounted on an array of extracellular microelectrodes as described previously (Field et al., 2007; Sekirnjak et al., 2008). Briefly, eyes were removed from macaque monkeys (Macaca sp.) of either sex that were terminally anesthetized in the course of other experiments. The vitreous humor and anterior portion of the eye were removed immediately in room light and the eye cup was stored in darkness in warm, oxygenated, bicarbonate-buffered Ames' solution (Sigma). A $\sim 1-2 \mathrm{~mm}$ diameter segment of retina was isolated and placed RGC side down on a custom multi-electrode array and held in place with a dialysis membrane positioned against the photoreceptor side. Data reported in this paper were compiled from 12 retinal preparations with eccentricities ranging from 7 to $15 \mathrm{~mm}$ taken from 11 macaque monkeys. These eccentricities correspond to visual angles of $31.4,36.2,36.2,38.6,41.1,41.1$, and $43.5^{\circ}$ (temporal retina) and 46.0/ $38.1,58.7 / 53.9,61.3 / 50.7,63.9 / 62.5$, and $71.8^{\circ} / 65.9^{\circ}$ (nasal retina; eccentricity/temporal equivalent eccentricity) (Drasdo and Fowler, 1974; Chichilnisky and Kalmar, 2002).

Dissections were performed primarily under infrared illumination, with a brief period $(<5 \mathrm{~min})$ of dim red illumination while mounting the array in the stimulation and recording system. Once mounted, the preparation was continuously superfused with oxygenated Ames' solution maintained at $\sim 33^{\circ} \mathrm{C}, \mathrm{pH}$ 7.4. The mean spike rate of the preparation was allowed to stabilize before commencing data collection. Voltage was recorded at $20 \mathrm{kHz}$ on all electrodes, bandpass filtered between either 43 and $2000 \mathrm{~Hz}$ or 43 and $5000 \mathrm{~Hz}$ ( $-3 \mathrm{~dB}$ ), and stored for off-line analysis.

The electrode arrays used in this study have been described previously (Litke, 1998; Sekirnjak et al., 2006). They consisted of 61 indium tin oxide electrodes on a glass substrate, arranged in an approximately hexagonal lattice with $60 \mu \mathrm{m}$ inter-electrode spacing within each row of electrodes and $60 \mu \mathrm{m}$ between rows. Electrodes were electroplated with platinum black (Cunningham et al., 2001) before each experiment, with resulting platinum electrode equivalent circular diameters of $\sim 11-19 \mu \mathrm{m}$. Light microscope images of electrodes were taken before each experiment for measurement of electrode areas.

Electrical stimulation. A custom 64-channel stimulation and recording system with stimulation artifact suppression (Hottowy et al., 2008, 2012) was used to apply the electrical stimuli and record RGC responses to visual and electrical stimuli. The electrical stimuli consisted of chargebalanced triphasic current pulses with phase durations of either 50 or 100 $\mu \mathrm{s}$ (150 or $300 \mu$ s total pulse duration). The sequence of relative current amplitudes for each phase was 2:-3:1 (anodal/cathodal/anodal). This pulse shape was chosen to minimize the electrical artifact generated by the stimulus (Hottowy et al., 2010, 2012), which in combination with the artifact-suppression circuitry, allowed the recording of submillisecond latency responses, even on the same electrode that was used for current injection (see Fig. 2A). Reported pulse amplitudes correspond to the charge of the cathodal phase. All current pulses were monopolar, with a platinum wire encircling the recording chamber serving as the return electrode.

Electrical stimuli used to measure thresholds, selectivity, and response latencies consisted of pulses applied sequentially through each individual electrode of the array in a pseudorandom order with 7.5 or $15 \mathrm{~ms}$ between pulses. The ordering of stimuli was restricted such that successive stimulation electrodes were at least $120 \mu \mathrm{m}$ apart to reduce the likelihood of stimulating the same neuron(s) in sequential pulses. Fifty repetitions were applied to each stimulation electrode at each tested pulse amplitude, with $10 \%$ increments between successive amplitudes. Electrical stimuli used to check for long-latency responses consisted of pulses applied at 5 $\mathrm{Hz}$ on individual chosen electrodes, and contained either 25 or 50 repetitions at each pulse amplitude.

Visual stimulation. To measure visual response properties for cell type identification, a dynamic white noise stimulus was used, in which the color and intensity of each square stimulus pixel in a lattice was randomly and independently varied (Chichilnisky, 2001). The visual stimulus was optically reduced and focused onto the photoreceptor outer segments, and one of two neutral density filters was used to maintain the stimulus at a low photopic intensity (Field et al., 2007). The resulting light level corresponded to 537, 225, 234 and 115 photoisomerizations/photoreceptor/s for rods, $\mathrm{L}$ cones, $\mathrm{M}$ cones, and $\mathrm{S}$ cones respectively, or a factor of $\sim 1.5$ above these values in some experiments (Baylor et al., 1984, 1987). Visual response data were collected for $30 \mathrm{~min}$, digitized at $20 \mathrm{kHz}$, and stored for off-line analysis.

Spike sorting and cell type classification. Recorded spike waveforms were detected and clustered into groups representing spikes from distinct RGCs, as described previously (Litke et al., 2004; Field et al., 2007). In the preparation presented in Figure 1, a modified spike-sorting algorithm was used, in which identified spike waveforms were iteratively subtracted from the recorded voltage traces as they were identified (M. Greschner, personal communication).

Once the spikes were identified and clustered, a linear estimate of the spatiotemporal receptive field of each cell was determined by calculating the spike-triggered average (STA) visual stimulus from the white noise sequence (Chichilnisky, 2001). Cells were classified based on their light response properties and electrical properties as described previously (Field et al., 2007). Briefly, five functionally distinct groups of cells were distinguished on the basis of their receptive field size, light response dynamics, chromatic sensitivity, and spiking auto-correlation. The mosaic organization of the receptive fields of each group of cells confirmed its correspondence to a single morphologically distinct cell type. The cell type identity of each group was obtained by comparison to published data on receptive field size, contrast gain, and response kinetics (Chichilnisky and Kalmar, 2002). In addition, cell type identities were confirmed by comparison of their density to the density of the major RGC types in the primate retina (Silveira and Perry, 1991; Dacey, 1993a,b, 2003; for review, see Dacey, 2004).

In figures, each STA is summarized by the 1.25 SD elliptical boundary of a Gaussian fit to the spatial profile of the STA. The punctate nature of the SBC STAs, due to their selective sampling of $S$ cones, resulted in poor Gaussian fits in some cases. To represent the boundary of the receptive field for these cells, STAs were blurred with a Gaussian filter before fitting. The expansion of the fits caused by this filtering was corrected by scaling the resulting elliptical fits of all SBCs within the preparation by a common scale factor. For each preparation, this scale factor was chosen to maintain the mean area of STA fits of those cells that exhibited qualitatively similar fits for the original and blurred STAs.

Electrical image. An electrical image (EI) of the spiking of each cell (Litke et al., 2004; Petrusca et al., 2007) was calculated to estimate its location and to facilitate the matching of electrically elicited spikes with cells identified during visual stimulation (see below). The EI of a cell consisted of the average voltage waveform generated by a spike from the cell on each electrode of the array. This electrical "footprint" of the cell typically consisted of high-amplitude biphasic voltage waveforms on a cluster of 1-3 electrodes apparently generated by the soma and dendrites, and smaller, triphasic, delayed waveforms on a series of electrodes ex- 
tending away from this region, apparently reflecting action potential propagation along the axon.

Analysis of electrically elicited responses. Recorded responses to electrical stimulation were typically superimposed on an artifact generated by the stimulus, precluding the use of automated threshold-based algorithms to identify and sort RGC spikes. Instead, spikes were identified using a combination of automated and manual voltage trace sorting, as described below.

First, a custom automated algorithm grouped traces into two categories. These categories were as follows: (1) failures, traces that were more similar (in a least-squared sense) to the artifact estimate alone and (2) successes, traces that were more similar to the sum of the artifact estimate and the spike waveform template recorded during light stimulation, at one of a range of potential time offsets from the artifact. The potential range of spike offsets was typically limited to the first $1.75 \mathrm{~ms}$ following stimulus onset based on typical observed latencies for somatic stimulation (Fig. 2) and axonal stimulation (data not shown). The group of traces categorized as failures was then used to generate an updated artifact estimate and the categorization step was repeated.

The results produced by the automated algorithm were visually inspected for several classes of errors, and manual corrections were implemented as necessary. In some cases, poor initial artifact estimates prevented the algorithm from converging on the correct categorization, necessitating selection of a new initial artifact estimate. For example, a poor initial artifact estimate could result in incorrect categorization of all traces as containing a spike when in fact no spikes were present. These cases were easily identified by the absence of current amplitudes containing partial activation (i.e., a transition from near-zero to near-one response probability between subsequent current amplitudes) or by the existence of spontaneous activity that would otherwise violate the refractory period of the cell.

In cases in which other cells with a similar spike waveform were recorded on the chosen electrode, the automated algorithm often incorrectly classified spikes from those cells as spikes of the cell being analyzed. Comparison of the artifact-subtracted signal on neighboring electrodes with the EI waveforms of the cell being analyzed versus other nearby cells typically allowed unambiguous identification of the origin of the spike.

Some electrical stimuli elicited spikes in more than one cell. In cases in which the response curves of these cells were non-overlapping (i.e., the cells exhibited well-separated activation thresholds) and the cell being analyzed had the largest threshold, the spike waveforms of cells with lower thresholds were subtracted along with the artifact estimate. In cases with overlapping response curves, the traces were categorized into multiple groups: those containing only artifact, those containing spikes of each cell alone, and those containing spikes of more than one cell (Hottowy et al., 2012). This was performed either by manual sorting or by running the automated algorithm above using spike waveforms from all activated cells instead of only the cell being analyzed.

In some cases, it was impossible to distinguish between traces containing and not containing a spike from the cell being analyzed. This occurred when the signal-to-noise ratio was too low to distinguish successes from failures, when the similarity of EIs of multiple cells precluded unambiguous determination of which spikes originated from the cell being analyzed, or when amplifier saturation masked part of the recording. Typically these situations only occurred when analyzing cells with very low-amplitude EI signals or at high pulse amplitudes. In these cases, response probabilities could not be determined.

To ensure that the manual correction was not influenced by the individual performing the analysis, the response curves of 10 test cells, one "easy" cell and one "difficult" cell for each of the five cell types, were independently analyzed by two individuals with only a general understanding of the purpose of the experiments. The mean difference in the threshold measured for the 10 test cells compared with the author's analysis was 0.55 and $0.65 \%$ for the two individuals, with a maximum threshold difference of $3.94 \%$ for a single cell.

Latency measurements and fits. Latencies were measured as the time between stimulus pulse onset and the negative peak of the somatic spike signal. For simplicity, analysis of response latencies was limited to two of the tested stimulus amplitudes for each RGC; specifically, the two ampli- tudes that activated the RGC with response probabilities closest to 0.5 . Response latencies were pooled across the two stimulus amplitudes (number of spikes ranged from 26 to 72 ) and binned into $25 \mu$ s intervals to generate a post-stimulus time histogram (PSTH) for each cell. To quantify spike latency precision, a smooth function was fitted to each PSTH:

$$
f(t)=\alpha\left(\frac{t-t_{0}}{\tau}\right)^{n} e^{-n\left(\frac{t-t_{0}}{\tau}-1\right)},
$$

where $n$ and $\tau$ control the shape of the function, $t_{0}$ represents the response latency and $\alpha$ the response amplitude. The functional form resulting from $n=3$ provided an accurate fit to the PSTHs and was used for all cells. The values of $\tau, \alpha$, and $t_{0}$ were constrained to be positive. The full-width at half-maximum (FWHM) was determined for each fit as a measure of response latency variability, and the mean across all cells is reported.

Threshold measurement. Threshold values were extracted by fitting a cumulative Gaussian (sigmoidal) function to a set of response probabilities measured over a range of pulse amplitudes. The maximum likelihood curve parameters were determined using a standard nonlinear optimization algorithm (Nelder-Mead). Because spontaneous spikes that occurred in the first $1.75 \mathrm{~ms}$ following stimulus onset were not distinguished from electrically elicited spikes, there were often nonzero response rates for stimuli far below threshold that could influence the likelihood of the fits. To reduce this influence, the fit was performed iteratively, using only data from the range of pulse amplitudes that corresponded to $0.1-0.9$ response probability of the curve fit. In cases in which this iterative fitting failed to converge to a single range of tested pulse amplitudes (e.g., oscillation between two or more ranges of amplitudes), the union of these ranges was used.

In some cases, response probabilities could not be determined over the entire pulse amplitude range required to capture the full response curve, either because it was not possible to distinguish between traces with and without a response for some pulse charge amplitudes (see above) or because only part of the response curve fell within the tested pulse amplitude range. To limit potential threshold biases due to incomplete measurements, target cells that did not reach a response probability of at least 0.4 for at least one analyzed pulse amplitude were not included as stimulated target cells in the threshold and selectivity analyses. Note that this requirement was not imposed on non-target cells investigated in the selectivity analysis.

Selection of target cells and stimulation electrodes. For the analysis of activation thresholds and selectivity, an attempt was made to only target cells with somas positioned over the array. Because soma positions were not directly measured, the EI of each cell (see above) was used to estimate which of the cells detected in a given recording had somas positioned over the array. Cells that likely did not lie over the array appeared in the recording as either pure axonal signals, characterized by small triphasic voltage waveforms, or as small signals recorded by electrodes on the edge of the array. The criterion used to classify a cell as lying over the array was that the maximum somatic signal either (1) was detected on a non-edge electrode or (2) had an amplitude that was $>50 \%$ of the mean peak signal amplitude of all of the cells of the same type that met the first criterion. Note that non-target cells analyzed for potential activation in the selectivity analysis were not limited to cells classified as lying over the array.

Many cells could be activated by more than one stimulation electrode. In such cases, a search was performed to locate the stimulation electrode that resulted in the lowest local activation threshold for the cell, and all threshold and selectivity results were reported for this electrode. The search initially included the electrode with the highest amplitude EI signal (approximate soma location) and all neighboring electrodes. If the lowest detectable threshold was in response to one of the neighboring electrodes, all electrodes neighboring this new "center" stimulation electrode were also checked. When a neighboring electrode could not be analyzed through the range of pulse amplitudes necessary to determine whether it exhibited a lower threshold, all electrodes neighboring this additional electrode were also checked for lower activation thresholds. This search was continued until a local minimum threshold was found. 
The stimulation electrodes located using this search method were typically close to the estimated soma position or slightly displaced along the direction of the axon. In over half $(62.1 \%)$ of the cases, the resulting stimulation electrode was the same as the initial electrode (the electrode with the peak EI signal). The mean distance between the initial electrode and stimulation electrode was $29 \mu \mathrm{m}$.

While reported thresholds are based on stimulation with electrodes located as close as possible to the region of peak sensitivity of each cell, stimulation electrode position was limited to the $60 \mu \mathrm{m}$ lattice of electrodes on the electrode array. As a result, the precise region of peak sensitivity of each RGC presumably lay somewhere between electrodes. Because of this lack of control over stimulation electrode position, and the fact that data from some stimulation electrodes could not be analyzed over the entire tested pulse amplitude range, the thresholds reported in Figure 5 should be considered an upper bound on the threshold achievable using electrodes of this diameter. Therefore, no statistical summary or comparison of thresholds in different cell types was attempted; instead all measurements are reported.

Selectivity analysis. Stimulation selectivity was assessed quantitatively in two preparations. In one preparation, complete or nearly complete mosaics of ON and OFF midget and ON and OFF parasol cells were recorded. In a second preparation, only the recorded populations of $\mathrm{ON}$ midget and $\mathrm{ON}$ parasol cells formed complete mosaics, so analysis was limited to these cell types. In both preparations, an attempt was made to selectively activate each recorded midget ganglion cell with a soma inferred to lie within the boundary of the array (see above). For each target midget cell, the stimulation electrode resulting in the lowest measurable threshold was first determined (see above). Every other recorded midget and parasol cell was then checked for activation by this stimulation electrode over the range of pulse amplitudes required to activate the target midget cell. For each target cell, the range of pulse amplitudes for which analysis of all non-target cells was possible is marked in gray in Figure 7. For two of the target cells, this analyzable range was not large enough to contain any portion of the target cell activation range (i.e., the target cell did not reach 0.2 response probability in the fully analyzable amplitude range); these cells were excluded from Figure 7.

Response probabilities plotted in Figure 6, $A, C$, and $E$, are based on direct measurement of the fraction of trials containing a spike within 1.75 $\mathrm{ms}$ from stimulus onset in all cases except one: response probability of the activated ON parasol cell in Figure $6 E$ is based on the response curve fit because a direct measurement could not be made for the pulse amplitude shown. All nonzero response probabilities for cells depicted in Figure $6, A, C$, and $E$, but without corresponding response curves in Figure $6, B, D$, and $F$, likely reflected spontaneous spiking, based on the fact that they did not exhibit the time-locking to the stimulus that is characteristic of direct electrical activation.

\section{Results}

To test the effectiveness of electrical stimulation in the major RGC types, we recorded and stimulated ganglion cells in isolated peripheral primate retina using multi-electrode arrays. First we identified the distinct cell types based on their light response properties, then we applied current pulses through the electrodes while recording the elicited activity.

\section{Cell-type classification}

Distinct RGC types were identified based on their visual response properties and spike train temporal structure as described previously (see Materials and Methods; Field et al., 2007). In all recordings, most of the recorded cells were classified as belonging to one of five functionally distinct groups. The receptive fields of each group tiled the region of retina recorded (Fig. 1), indicating that each group corresponded to a morphologically distinct cell type. The five most commonly observed types were identified as ON and OFF midget, $\mathrm{ON}$ and OFF parasol, and small bistratified based on cell density and visual response properties. These cell types comprise $\sim 75 \%$ of the visual signal transmitted to the brain. Occasionally, spiking ama-

\section{small bistratified}
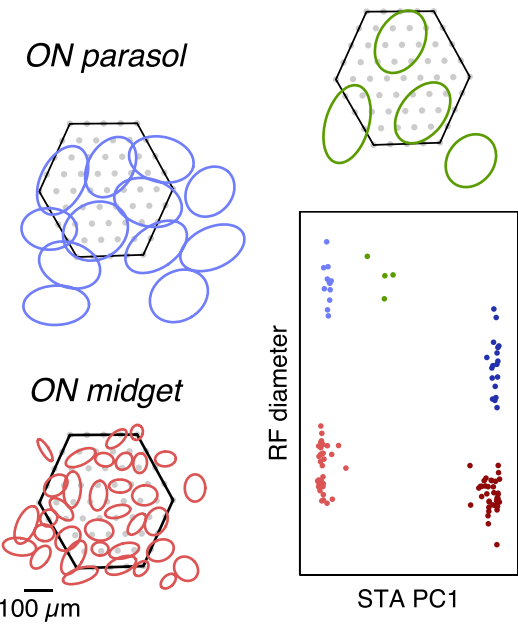

STA PC1

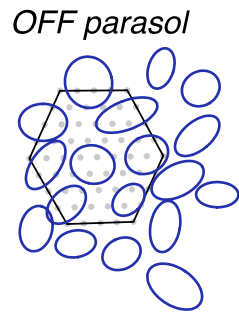

OFF midget

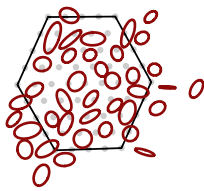

Figure 1. Identification of major RGC types in primate retina using visual response properties. Center, Receptive field (RF) diameter and the first principal component (PC1) of the STA time course were used to subdivide the cells recorded in a single preparation into distinct groups. Surrounding, RFs of cells in each group tiled visual space. Ellipses depict the 1.25 SD boundaries of Gaussian fits to the spatial component of the STA (see Materials and Methods). Hexagons represent the outline of the electrode array and filled gray circles indicate electrode positions. Some cells with RFs lying outside the array boundary were detected based on axonal signals (see Materials and Methods).

crine cells and ganglion cells of unknown types were encountered, but these were not studied further.

\section{Responses to electrical stimulation}

RGCs of each of the five major types were directly activated by brief, low-amplitude current pulses delivered through individual electrodes. The responses elicited in one sample cell of each type are summarized in Figure 2. The collection of voltage traces recorded during and immediately after 50 applications of a triphasic current pulse was typically separated into two distinct groups based on waveform (see Materials and Methods). These two groups corresponded to trials in which the cell fired a spike in response to the pulse (successes), and trials in which it did not (failures) (Fig. 2A). The electrical artifact produced by the current pulse was removed from all traces by subtracting the mean of the traces identified as failures. In each case, the resulting response waveform in each trial identified as a success closely matched the waveform of the spikes of a specific cell recorded during visual stimulation (Fig. $2 A$, dashed lines). The artifact-reduction circuitry built into the stimulation and recording system (Hottowy et al., 2008, 2012) and the triphasic current pulse shape reduced the artifact size significantly, avoiding amplifier saturation and revealing RGC spikes as early as $50 \mu$ s after current injection on the same electrode used to apply the current pulse as well as on other electrodes.

At sufficiently high pulse amplitudes, nearly all examined cells of each type could be stimulated reliably and with high temporal precision (Fig. 2B, also see below). Decreases in pulse amplitude resulted in a sigmoidal decline in the fraction of trials in which the cell responded (Fig. 2C) as observed in previous work (Sekirnjak et al., 2008; Fried et al., 2009; Tsai et al., 2009). In many cases, cells could be activated with high spatial selectivity: a particular pulse amplitude reliably activated one cell without activating any of the neighboring cells of that type (Fig. 2D; Sekirnjak et al., 2008). Selectivity is treated more extensively below.

Responses to electrical stimulation always occurred at low latency (Fig. 3), similar to previous results for electrical stimulation 
A
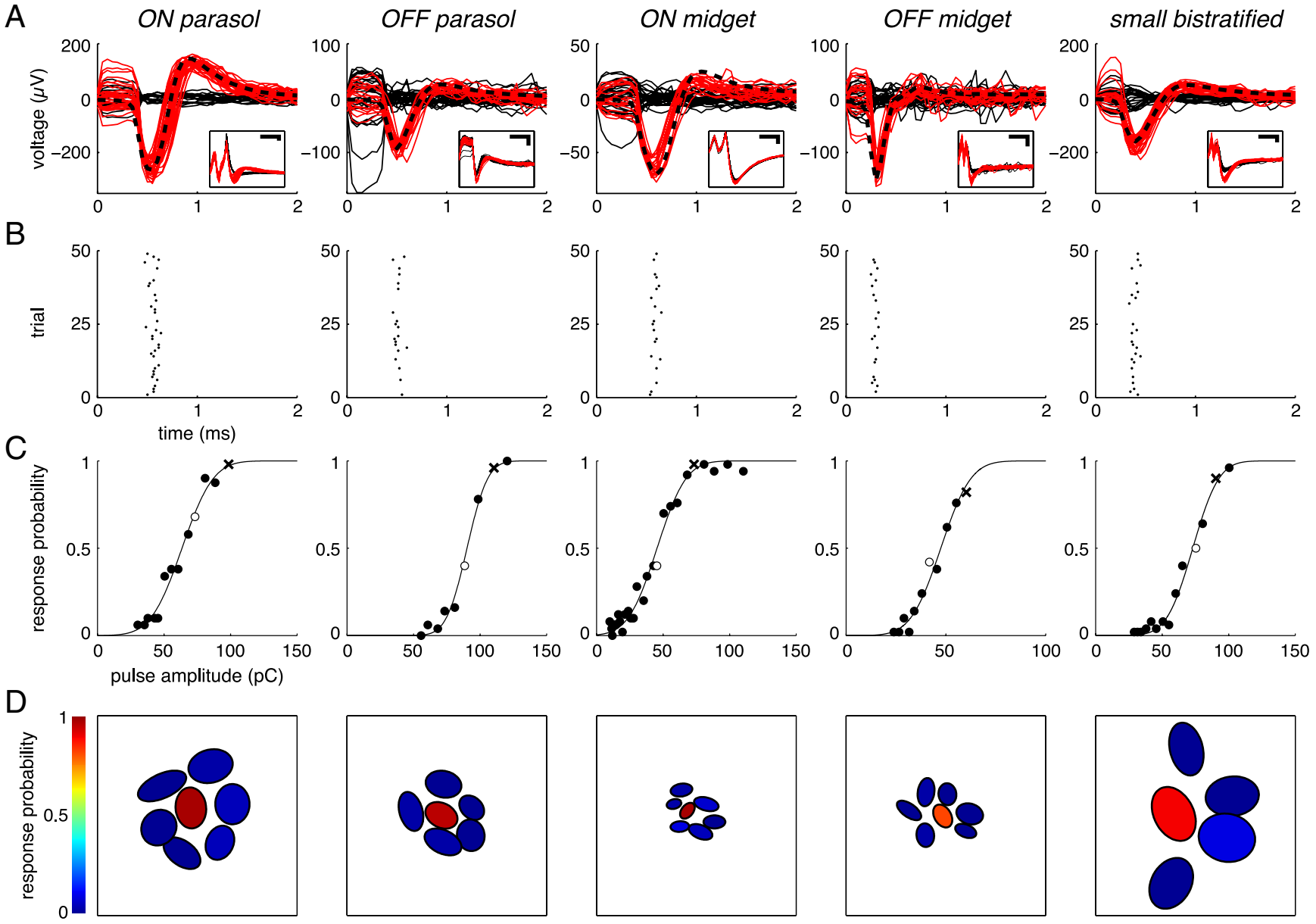

Figure 2. Cells from each of the five major primate RGC types exhibited single-spike, submillisecond responses to electrical stimulation and could be activated without activating neighboring cells of the same type. $A$, Overlaid raw (inset) and artifact-subtracted voltage traces (main axes) recorded during and immediately after 50 stimulation trials, with successes (traces containing a spike) in red and failures (traces containing only stimulus artifact) in solid black. Black dashed traces show the spike template of each cell, taken from the electrical image (see Materials and Methods). Voltage traces were recorded by the electrode used for stimulation in all examples except the $0 \mathrm{FF}$ parasol, in which voltage traces were recorded by a neighboring electrode. Scale bars: Insets, $0.5 \mathrm{~ms}$ and 100 $\mu V$. $\boldsymbol{B}$, Raster plots of responses shown in $\boldsymbol{A}$, with spike time defined as the negative peak of the spike waveform. $\boldsymbol{C}$, Response probabilities measured over a range of pulse amplitudes, fit by a sigmoidal function (see Materials and Methods). For each cell, open circle indicates pulse amplitude applied in $\boldsymbol{A}$ and $\boldsymbol{B}$, and " $x$ " indicates amplitude applied in $\boldsymbol{D}$. D, Selective activation of the example cell among neighboring cells of the same type. Each cell is represented by an elliptical fit to its receptive field, and the color of the fit indicates the fraction of trials in which the current pulse elicited a response.

of ON and OFF parasol RGCs (Sekirnjak et al., 2006; note the difference in spike time definition). Latencies from stimulus onset for all cells successfully activated in this study are summarized in Figure 3. For each cell, the mean latency was always below $1 \mathrm{~ms}$, and the variability in latency was low: the mean FWHM of PSTH curve fits was $76 \mu$ s. These short and reproducible latencies were previously found to reflect direct electrical activation of RGCs rather than indirect activation via retinal interneurons, and suggest that electrical stimulation has the capacity to faithfully reproduce the temporal code of retinal neurons (see Discussion).

To investigate the possibility of additional indirect, longerlatency responses due to electrical activation of interneurons, RGC activity was examined over a period of $100 \mathrm{~ms}$ following pulse onset for three cells of each type over a range of stimulus amplitudes, including those high enough to directly activate each cell with $>0.99$ probability. Of the 15 cells investigated, only one showed any sign of activation at latencies $>1 \mathrm{~ms}$. For this cell, a small fraction $(<20 \%)$ of the initial $<1$ ms latency spikes was followed by a second spike roughly $2 \mathrm{~ms}$ later. These second spikes were most likely a consequence of the intrinsic membrane dynamics of the cell, as has been observed previously (Sekirnjak et al., 2006), rather than indirect activation via retinal interneurons. This conclusion is based on two observations. First, later spikes only occurred at frequencies above chance levels in trials that contained a short-latency spike, suggesting that the first spike was required to elicit the second spike. Second, the relative timing of the second spike closely matched a peak in the auto-correlation function of the cell obtained during responses to visual stimulation, indicating that similar spike pairs frequently occurred in the absence of electrical stimulation (data not shown). In addition, a brief period (up to $50 \mathrm{~ms}$ ) of depression in spontaneous firing rate was observed in several cells following electrical activation (data not shown). The timing of these suppressive effects was consistent with relative refractory periods observed in the autocorrelation functions of the cells.

\section{Comparison of thresholds in different cell types}

To determine whether different RGC types exhibit different sensitivity to electrical stimulation, the thresholds for electrical activation of cells of each type were compared in four preparations. In each preparation, a subset of the five major cell types was examined because none of the preparations in which electrically 


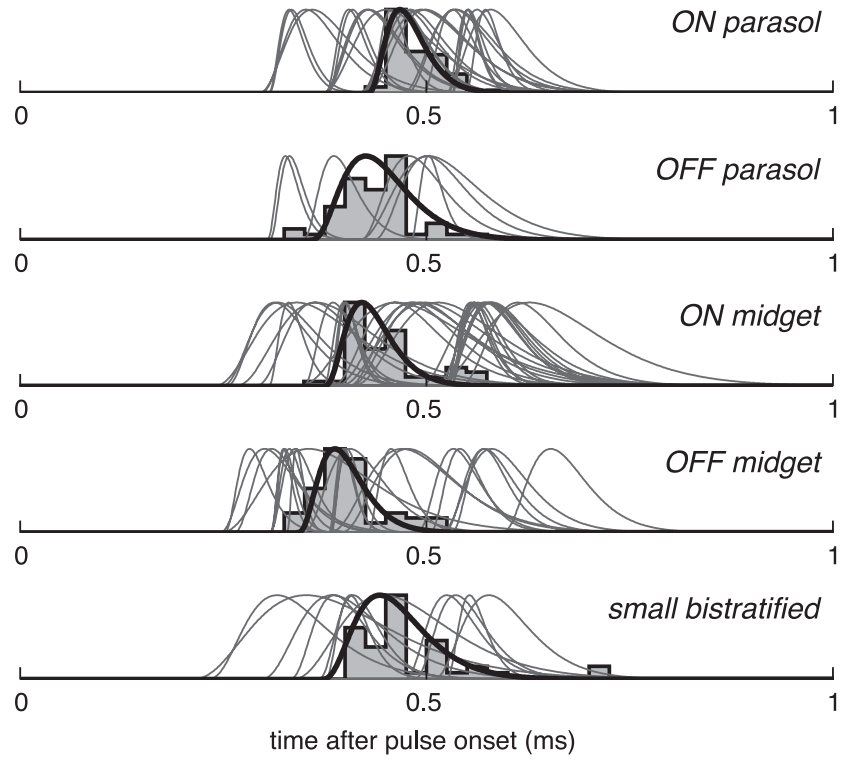

Figure 3. All cells activated by electrical stimulation responded with a precisely timed spike within $1 \mathrm{~ms}$ of stimulus onset. The PSTH of a representative cell from each cell type is shown with corresponding curve fit in black (see Materials and Methods). Fits to the PSTHs of all other cells are shown in gray. Spike times are defined by the negative peak of the spike waveform.

elicited responses were analyzed contained complete recordings of all five major cell types, and cell types with partial mosaics of receptive fields were not analyzed to avoid potential sampling bias. Threshold was defined as the pulse charge amplitude required to elicit spikes in 50\% of trials.

Initial examination of the responses of $\mathrm{ON}$ and OFF midget and $\mathrm{ON}$ and $\mathrm{OFF}$ parasol cells in a single retinal preparation indicates that these cell types have similar sensitivity to electrical stimulation. Responses of a representative cell of each of these types are shown in Figure 4. The threshold pulse charge amplitudes of these cells all fell within a twofold range. Comparison of thresholds within a preparation eliminated the potential influence of differences in health or physical placement of different retinal preparations.

The results of stimulation of all $\mathrm{ON}$ and OFF midget and $\mathrm{ON}$ and OFF parasol cells in this preparation are summarized in Figure $5 A$. Nearly all of the cells ( 38 of 42 ) were successfully activated within the tested pulse amplitude range, and the range of measured activation thresholds for the different cell types was largely overlapping. The examined cells represent essentially all of the $\mathrm{ON}$ and OFF midget and $\mathrm{ON}$ and OFF parasol cells in this retinal region, as indicated by the even tiling of receptive fields of each cell type (Fig. 4). An attempt was made to find the stimulation electrode that resulted in the minimum threshold for each cell; however, the actual minimum achievable threshold may be slightly lower due to limitations in the precise location of stimulation electrodes relative to the region of peak sensitivity of each cell (see Materials and Methods). ON and OFF midget ganglion cells exhibited a slightly broader distribution of thresholds than $\mathrm{ON}$ and OFF parasol cells.

Similar to the first preparation, the measured activation thresholds of midget and parasol cells in the second preparation overlapped significantly, with a slightly wider spread of midget thresholds than parasol thresholds (Fig. 5B). A smaller fraction of the $\mathrm{ON}$ midget ganglion cells in this preparation had measurable responses to electrical stimulation than in the first preparation. This is likely attributable to the fact that a smaller range of pulse amplitudes was applied in this preparation (Fig. 5, gray regions signify untested pulse amplitudes). This explanation is supported by the observation that the fraction of ON midget ganglion cells with thresholds falling below the maximum charge amplitude applied in the second preparation was similar in the first and second preparations (55.6 and 64.5\%, respectively).

To determine whether the sensitivity of SBCs to electrical stimulation is comparable to that of other cell types, two additional preparations with nearly complete recordings of SBCs were analyzed. In these preparations, analysis was limited to the $\mathrm{ON}$ parasols and the SBCs, using the ON parasol cells as a benchmark. The range of SBC thresholds was similar to the range of $\mathrm{ON}$ parasol thresholds in these preparations (Fig. 5C,D). The fact that the ON parasol and SBC thresholds measured in the fourth preparation were slightly higher than the thresholds in the other three preparations highlights the importance of within-preparation comparisons. The overlap between SBC and ON parasol threshold ranges within these two preparations suggests that the sensitivity of SBCs to electrical stimulation is similar to the other four cell types examined in this study.

A common concern regarding the use of small-diameter electrodes for electrical stimulation is the safety of the charge densities required to activate cells. In this study, all measured activation thresholds fell well within the commonly cited platinum charge density limit of $0.3-0.35 \mu \mathrm{A} / \mathrm{cm}^{2}$ (Brummer and Turner, 1977), and the majority of thresholds fell within the more conservative $0.1 \mathrm{mC} / \mathrm{cm}^{2}$ platinum charge density limit (Fig. 5, dashed lines; see Discussion; Rose and Robblee, 1990).

\section{Spatial selectivity}

Veridical recreation of natural RGC activity is likely to require independent activation of different cells. A clear demonstration of independence would be selective activation of a single cell without simultaneous activation of neighboring cells of any type. While previous work has shown that individual ON and OFF parasol cells can be selectively activated without activating neighboring parasol cells (Sekirnjak et al., 2008), these two cell types make up only $\sim 16 \%$ of the total number of primate RGCs (for review, see Dacey, 2004). Similarly, each example of selectivity above (Fig. 2) focused exclusively on cells of one type. As a result, it is still unclear whether a single cell can be selectively activated without activating any other cells of the highest-density RGC types. In particular, selective activation of $\mathrm{ON}$ and OFF midget ganglion cells, which comprise an additional $\sim 52 \%$ of RGCs, is expected to be a greater challenge.

As a test of spatial selectivity, every individual midget cell lying over the array was probed to determine whether it could be activated without also activating any other cells of the same type or other types. A range of selectivity across cells was revealed by this analysis. Three example target cells illustrating this range are shown in Figure 6. The first (Fig. 6A,B) is an example of complete selectivity. The response probabilities of the target OFF midget cell, along with all other ON and OFF midget and parasol cells recorded in this preparation, are shown for a stimulation electrode and pulse amplitude that reliably activated the target cell (Fig. 6A). While the target cell was activated in essentially all of the trials, none of the other ON or OFF midget or ON or OFF parasol cells in the region responded to the current pulse.

The second example (Fig. 6C,D) illustrates a case of partial selectivity. In this example, the target $\mathrm{ON}$ midget cell was activated at lower pulse amplitudes than any other midget or parasol cell. However, one non-target cell (OFF midget) was activated by this stimulation electrode, although its response curve overlapped 
only slightly with that of the target cell (Fig. $6 D)$. At a pulse amplitude sufficient to reliably activate the target cell, the non-target cell responded in only a small fraction of the trials (Fig. 6C).

The final example target cell could not be selectively activated (Fig. $6 E, F$ ). In this case, two non-target cells (ON parasol, OFF midget) were activated at lower pulse amplitudes than the target cell, and a third nontarget cell (OFF parasol), was activated at slightly higher but still largely overlapping pulse amplitudes (Fig. 6F). The response probability for each of these cells, along with all other ON and OFF midget and parasol cells recorded in this preparation, are shown for a stimulus amplitude near the threshold of the target cell (Fig. 6E). The non-target $\mathrm{ON}$ parasol and OFF midget cell were more strongly activated than the target $\mathrm{ON}$ midget cell at this amplitude, and the nontarget OFF parasol was weakly activated.

The fact that the activated non-target cells in these examples had receptive fields positioned close to the corresponding stimulation electrodes (Fig. $6 A, C, E$, open circles) suggests that each was stimulated at or near its soma. This was verified in all but one case by examining the putative soma location of each activated nontarget cell, based on the location of peak voltage deflection of the EI of the cell (data not shown), a proxy for soma location. However, in other cases, including the activated $O N$ parasol in Figure $6 E$, the putative soma location of the activated non-target cell was distant from the stimulation electrode. All such cases appeared to be attributable to axonal stimulation, a conclusion based on proximity of the stimulation electrode to the axon of the activated non-target cell inferred from the EI (data not shown). In total, axonal stimulation, classified as activation in which the stimulation electrode was $>150 \mu \mathrm{m}$ from the peak somatic signal of the non-target cell, accounted for approximately half of the total number of cases of nontarget activation in this study. It is expected that many additional axons, originating from distant RGCs not recorded in these preparations, were present and potentially activated, an important issue in the design of epiretinal prostheses (see Discussion).

The selectivity results for all of the ON and OFF midget cells in this preparation are summarized in Figure 7 (left column). Data from each cell are summarized by the activation range: the range of pulse amplitudes corresponding to $0.2-0.8$ response probability for that cell and stimulation electrode. Half (16) of the total number of midget ganglion cells positioned over the array in this preparation could be activated with high selectivity: specifically, high target cell response probability $(>0.8)$ without significant $(>0.2)$ response probability of any non-target cells. The overall selectivity achievable when targeting $\mathrm{ON}$ midget cells was qualitatively similar to the selectivity achievable for OFF midget target cells.

A
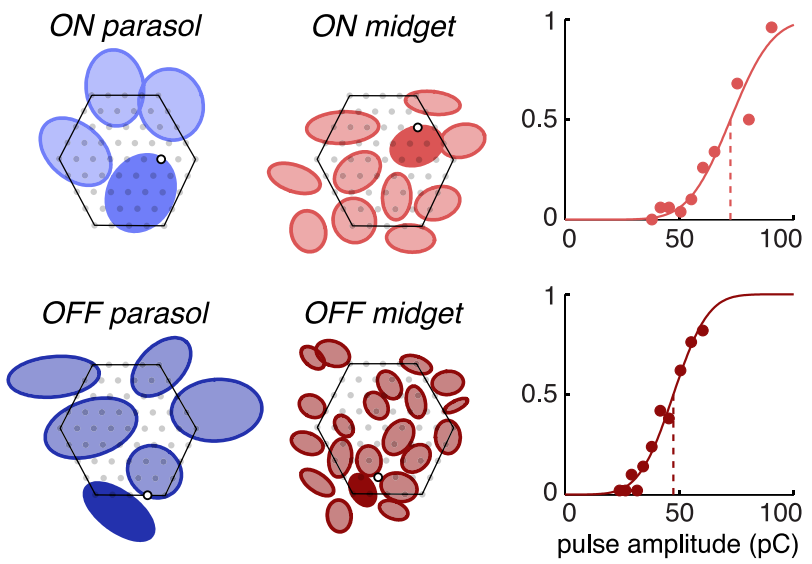

Figure 4. ON and OFF parasol and midget cells in a single preparation exhibited similar activation thresholds. Response curve of one representative cell of each type is shown. Receptive fields of cells positioned over the array are depicted as elliptical fits (Fig. 1)

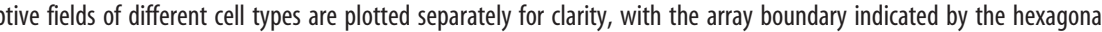
responding stimulation electrode is depicted as an open black circle and the positions of the remaining electrodes are indicated

Figure 5. Comparison of measured activation thresholds of different cell types within four preparations. $\boldsymbol{A}$, Thresholds of all activated cells from the preparation represented in Figure 4. Thresholds corresponding to example response curves shown in Figure ions. Values in parentheses indicate the fraction of cells lying over the array with measurable thresholds. Dashed vertical lines mark the conservative platinum charge density limit of $0.1 \mathrm{mC} / \mathrm{cm}^{2}$ (see Discussion) based on the mean planar area of the electrodes used in each preparation. Gray regions indicate untested ranges of pulse amplitudes.

In the second preparation, a smaller proportion of the midget cells positioned over the array could be verifiably activated with high selectivity ( 11 of 31 ). This is most likely due to the fact that the maximum charge amplitude applied in this preparation was only approximately half of the maximum charge amplitude applied in the first preparation. As a result, approximately one-third of the midget cells was not activated above threshold (see above, Comparison of thresholds in different cell types), and an additional four cells with measurable thresholds could have potentially been activated with full selectivity at higher charge amplitudes but could not be investigated through their entire activation range (Fig. 7, bottom four target cells of right column). When considering only the target cells that could be analyzed through their entire activation range, the proportion of selectively activated cells in the first and second preparations was similar (16 of 26 and 11 of 17 , respectively). Note, however, that only ON midget and ON parasol cells were examined in the second preparation. 

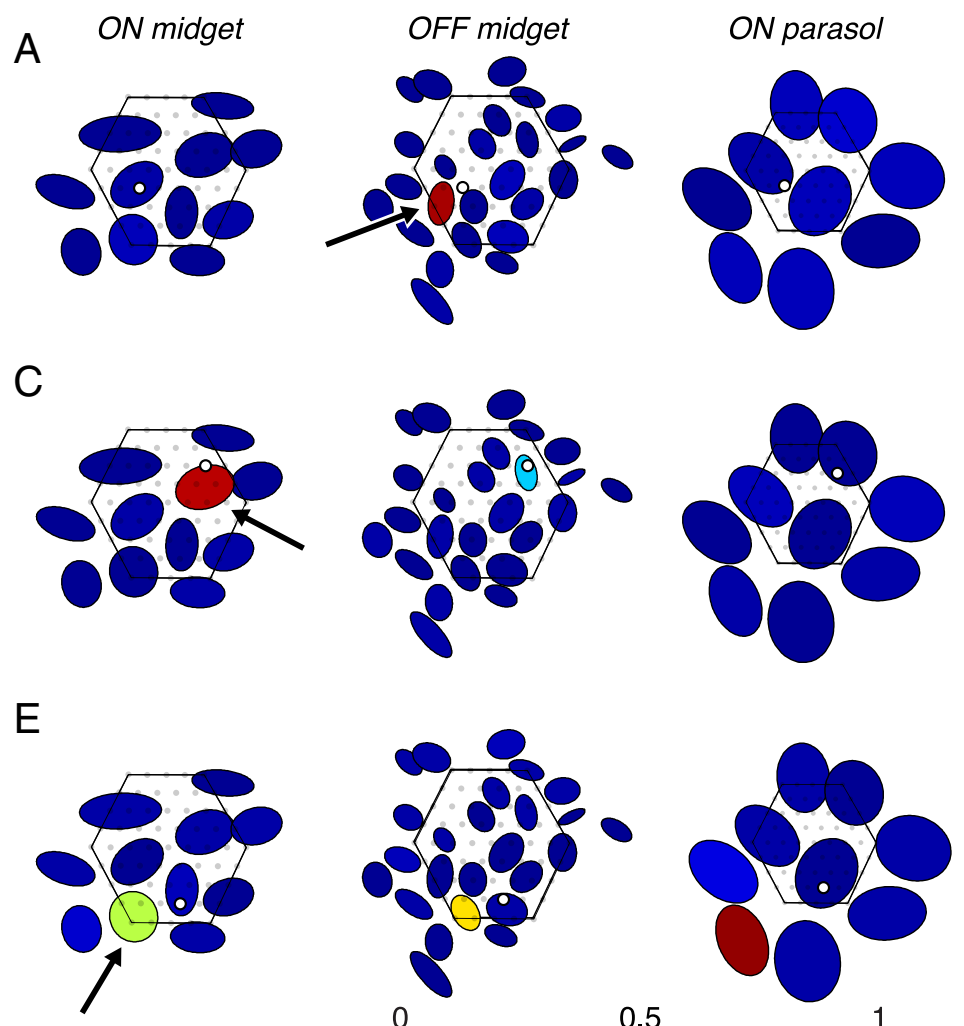

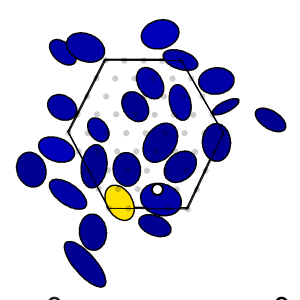

0

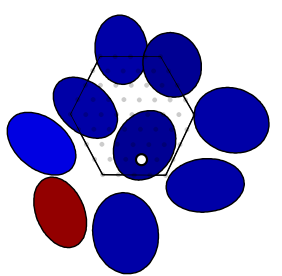

1
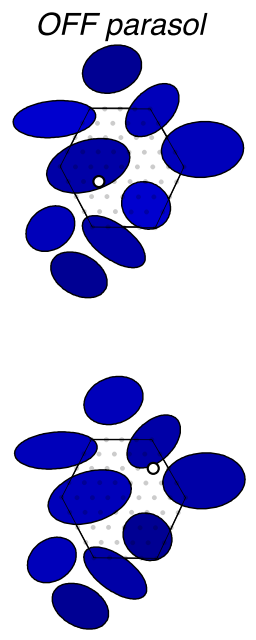

D

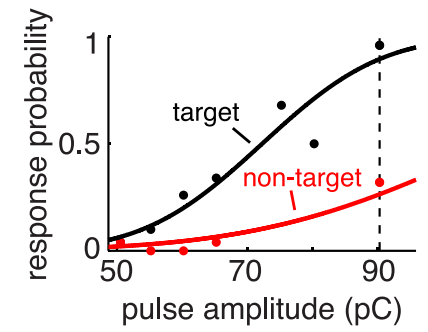

$\mathrm{F}$

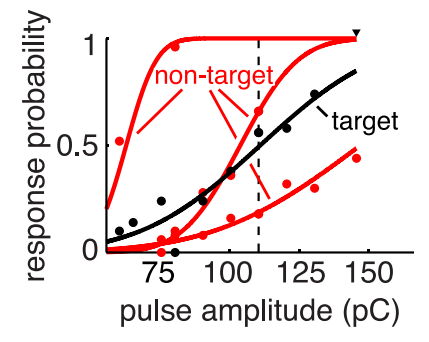

response probability

Figure 6. Examples of cell selectivity in electrical activation. $A, C$, and $\boldsymbol{E}$, Response probability of each cell in a single recording for a specific stimulation electrode and pulse amplitude. Cells are represented by elliptical fits to their visual receptive fields (Fig. 1), and each target cell is marked with an arrow. Fill colors indicate response probabilities. Mosaics of receptive fields are separated and midget mosaics are enlarged $25 \%$ relative to parasol mosaics for clarity. The position of each stimulation electrode is depicted as an open black circle, and non-stimulation electrodes are shown as filled gray circles. The outline of the array is indicated with a hexagon. $\boldsymbol{B}, \boldsymbol{D}$, and $\boldsymbol{F}$, Response curves of activated cells. Vertical dashed lines indicate pulse amplitudes plotted in $\boldsymbol{A}, \boldsymbol{C}$, and $\boldsymbol{E}$. Nonzero response probabilities for cells in $\boldsymbol{A}, \boldsymbol{C}$, and $\boldsymbol{E}$ not represented in $\boldsymbol{B}, \boldsymbol{D}$, and $\boldsymbol{F}$ were $\leq 0.08$ and were consistent with spontaneous activity (see Materials and Methods).

\section{Discussion}

The five highest-density RGC types were activated by brief epiretinal current pulses applied with a high-density multi-electrode array in isolated peripheral primate retina. All stimulated cells exhibited precisely timed spiking responses characteristic of direct RGC activation. In general, the activation thresholds fell within conservative charge density limits for platinum electrodes. Within-preparation comparisons of thresholds revealed similar sensitivity to electrical stimulation in the different cell types. Selective activation of a single RGC without activation of its neighbors was possible in some cases, while in other cases neighboring somas and/or axons were also activated.

\section{Direct RGC activation}

The precisely timed, submillisecond latency, single-spike responses observed in this study are characteristic of direct RGC activation by the electrical stimulus (Fried et al., 2006; Sekirnjak et al., 2006; Tsai et al., 2009). In some stimulation paradigms, epiretinal stimulation indirectly elicits RGC activity via activation of presynaptic cells. Such activity is typically characterized by one or more bursts of activity at latencies $\geq 3 \mathrm{~ms}$ (Jensen et al., 2005; Ahuja et al., 2008). There was no evidence for indirect excitation of RGCs in the 15 cells examined for responses over a $100 \mathrm{~ms}$ period following the stimulus (see Results).

The absence of indirect responses in this study is not surprising, given the short pulse widths used. It has been well established that shorter pulses preferentially elicit direct RGC responses in comparison with longer pulses (Greenberg, 1998; Fried et al., 2006; Margalit and Thoreson, 2006; Ahuja et al., 2008).

\section{Activation thresholds}

Because different RGC types convey distinct visual information to different regions of the brain (for review, see Dacey, 2004; Field and Chichilnisky, 2007), an understanding of how each specific cell type responds to electrical stimulation is crucial to the development of effective retinal prostheses. In addition, it may be possible to exploit particular differences in response properties, if they exist, to preferentially activate certain cell types. A number of cell type-specific characteristics could potentially influence sensitivity to electrical stimulation. Different RGC types have been shown to have distinct intrinsic membrane properties (Margolis and Detwiler, 2007; for review, see Ishida, 2003). Differences in the length of the band of high sodium channel density in the axon initial segment, the region thought to be most sensitive to electrical stimulation, have been observed in rabbit (Fried et al., 2009). Because most of these characteristics have not been measured directly in primates, it is difficult to know what effect they might have on the response properties of the RGC types examined here.

Previous reports of direct activation thresholds of different RGC types have been inconsistent. A recent study reporting the thresholds of three rabbit RGC types (Fried et al., 2009) showed significant differences between types. In contrast, other studies report no significant differences in direct stimulation threshold between putative cell types in rabbit (Tsai et al., 2009) or mouse 
(Margalit et al., 2011), although the reported groupings probably represent groups of cell types, potentially masking sensitivity differences between the true individual cell types. Finally, a study comparing $\mathrm{ON}$ and $\mathrm{OFF}$ parasol RGCs in primate found no significant difference in direct activation threshold (Sekirnjak et al., 2008).

In the current study, no clear differences in direct activation thresholds between cell types were observed. There are at least two possible explanations for the difference between the current results and those reported in Fried et al. (2009). First, at least two of the three cell types examined in the Fried study (ON-OFF direction selective, local edge detector) are, based on their light response properties, not homologous to the primate cell types examined in this study, so the different result could arise from the existence of sensitivity differences between certain RGC types but not others. Second, the distance between the stimulation electrode and the region of highest sensitivity of each RGC was less controllable in the present study; the electrode positions were constrained to a fixed grid with 60 $\mu \mathrm{m}$ spacing, whereas the previous study searched for the threshold minimum using $10 \mu \mathrm{m}$ steps. This experimental constraint may have introduced threshold variability that could have obscured small differences between cell types.

\section{Stimulation safety}

The use of small electrodes in neural prosthetics can be damaging to both electrodes and neural tissue if the charge densities required to activate cells generate irreversible electrochemical reactions at the electrode surface (for review, see Merrill et al., 2005). A study of brief pulses injected through platinum electrodes (Rose and Robblee, 1990) measured a conservative charge density limit of $0.1-0.15 \mathrm{mC} / \mathrm{cm}^{2}$ (cathodal-first biphasic) or $0.05-0.1 \mathrm{mC} / \mathrm{cm}^{2}$ (anodal-first biphasic). Because the pulse shape used in this study was triphasic, we compared our activation thresholds to the midpoint of these values: $0.1 \mathrm{mC} / \mathrm{cm}^{2}$. In this study, the threshold charge densities for activation of the majority of cells based on planar electrode areas fell within this limit. However, the $0.1 \mathrm{mC} / \mathrm{cm}^{2}$ charge density limit is relatively conservative; other studies examining the charge density necessary to generate significant adverse electrochemical reactions at the surface of platinum electrodes have suggested that densities of up to $0.30-0.35 \mathrm{mC} / \mathrm{cm}^{2}$ are safe for longer pulses (Brummer and Turner, 1977), and a recent study of high-frequency stimulation in rat retina with platinum electrodes found no significant histological changes to the retina at all tested charge densities, up to $0.68 \mathrm{mC} / \mathrm{cm}^{2}$ (Ray et al., 2011). Finally, other electrode materials such as iridium oxide may be used in place of platinum to extend the range of charge densities that can be injected without inducing unwanted electrochemical reactions at the electrode surface (Beebe and Rose, 1988; Weiland et al., 2002). preparation 1

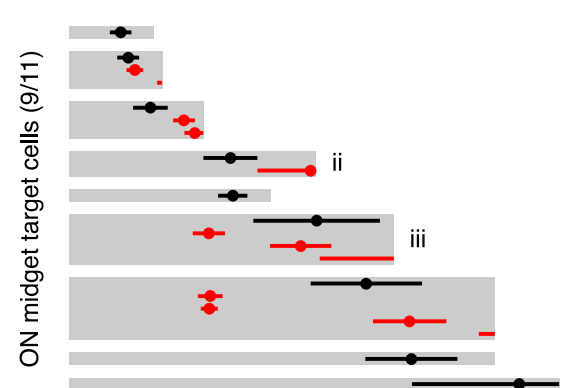

Figure 7. Approximately half of the midget cells in two preparations could be activated without also activating any other amplitudes that resulted in response probabilities between 0.2 and 0.8 (lower right inset). Selectivity attempts marked with $\mathrm{i}$, ii, and iii correspond to examples in Figure $6 A / B, C / D$, and $E / F$, respectively.

In addition to adverse electrochemical reactions occurring at the electrode surface, stimulation-induced tissue damage may occur as a direct result of exposure to electric fields, either due to excessive neural activation (for review, see Merrill et al., 2005) or disruption of cellular membranes from electroporation (Butterwick et al., 2007; Cohen et al., 2011). These mechanisms of damage are highly unlikely with the small electrodes and low pulse amplitudes used in this study. Excessive neural activation is unlikely, given that the stimuli used here typically elicited no more than one spike in a small number of cells. Damage attributable to electroporation also seems unlikely given that much higher currents can be sustained without membrane disruption (Butterwick et al., 2007). Specifically, for electrode diameters below $200 \mu \mathrm{m}$, the threshold for damage using a $600 \mu \mathrm{s}$ pulse width was $139 \mu \mathrm{A}$ regardless of current density, more than an order of magnitude higher than the current amplitudes used in the present study. Also, extrapolation of previous work (McCreery et al., 1990) to the small electrodes used in this study suggests that much higher charge densities can be applied before observable neural damage occurs.

\section{Spatial selectivity}

An ideal retinal prosthesis would be able to veridically recreate the natural spatiotemporal RGC activity patterns generated in a 
healthy retina in response to a visual scene. This would require precise control over the timing of spikes in individual RGCs. Highly precise temporal control of spike timing has been demonstrated (Fried et al., 2006; Sekirnjak et al., 2006, 2008; Hottowy et al., 2012), but it is less clear whether single-cell spatial resolution is possible, even with much higher-density electrode arrays than those used in current clinical prostheses. Studies examining the relationship between stimulation electrode position and direct RGC activation using electrodes similar in size to those used in this study have shown that the area of highest sensitivity of direct RGC activation is a localized region near the axon initial segment (Sekirnjak et al., 2008; Fried et al., 2009), with cathodal stimulation thresholds increasing as a power-law function of lateral distance with exponents of $\sim 2.5-3.2$ for distances $>50 \mu \mathrm{m}$. (Jensen et al., 2003). However, single-cell activation may still be difficult due to the large cell-to-cell variability in direct stimulation threshold and the high density of RGCs in the primate retina.

Few attempts have been made to directly record the RGCs that are activated by focal epiretinal stimulation. A recent study in salamander found that even small stimulation electrodes (10 $\mu \mathrm{m}$ ) simultaneously activated many RGCs over a relatively large retinal region, but the pulse widths used for these measurements $(\geq 400 \mu \mathrm{s}$ ) were shown to activate RGCs through a combination of direct and indirect stimulation (Behrend et al., 2011). A study in rat (Sekirnjak et al., 2006) found no direct activation of cells further than $60 \mu \mathrm{m}$ from the stimulation electrode when using stimuli with amplitudes slightly above the mean threshold $(\sim 0.1$ $\mathrm{mC} / \mathrm{cm}^{2}$ ). However, no attempt was made to measure the proportion of total RGCs that were recorded, and unrecorded cells may have been activated. More recent studies found that $\mathrm{ON}$ and OFF parasol cells of primate retina (Sekirnjak et al., 2008) and "OFF-1" cells of rat retina (Hottowy et al., 2012) could be individually activated. In these studies, the presence of clear mosaics of receptive fields was used to confirm that all cells of these types in the region were successfully recorded. However, these cell types only make up a small fraction of the total number of retinal ganglion cells present (e.g., parasol cells account for $\sim 16 \%$ of primate RGCs; for review, see Dacey, 2004), so it is possible that RGCs of other cell types that were not examined were activated.

The ON and OFF midget ganglion cells, which are the two numerically dominant cell types in the primate retina and are thought to mediate high-acuity vision, provide a more stringent test of single-cell selectivity. Together with the ON and OFF parasol cells, these cell types constitute $\sim 70 \%$ of the total number of retinal ganglion cells. The successful recording of complete or nearly complete populations of the examined cell types was confirmed in the current study based on receptive field tiling. In the two preparations examined in this study, selective activation was achievable in approximately half of the midget cells with detectible thresholds.

Putative axonal stimulation accounted for approximately half of the cells that were inadvertently activated when targeting a particular RGC. If axonal activation thresholds are relatively constant along their length as they course toward the optic nerve, it is likely that many additional axons, originating from distant RGCs not recorded in these preparations, were activated in at least a portion of the selective activation attempts. As a result, the proportion of cells that can be selectively activated in a full retina would probably be lower than these measurements suggest. In addition, the spatial selectivity analysis was performed on peripheral retina $\left(9-9.5 \mathrm{~mm}\right.$, corresponding to $41.1-43.5^{\circ}$ visual angle), where RGC density is relatively low. Selective activation would be more difficult to achieve in the central retina, where retinal prostheses are typically located.

The difficulty in selectively activating some of the individual RGCs under these conditions suggests that simple singleelectrode stimulation with an electrode array of $60 \mu \mathrm{m}$ or larger spacing will not be sufficient to veridically recreate natural RGC activity patterns on a cell-by-cell basis. Single-cell selectivity of all RGCs will require either higher-density electrode arrays, novel electrode geometries, or more sophisticated stimulation patterns (Grumet, 1999; Rattay and Resatz, 2004).

\section{Retinal degeneration}

Outer retinal degeneration could potentially influence the responses of RGCs to electrical stimulation with an epiretinal prosthesis. Due to the lack of primate models of outer retinal degeneration, only healthy retinal tissue was used in this study. Outer retinal degeneration results in extensive remodeling of the retinal circuitry (for review, see Jones and Marc, 2005). However, RGC morphology and intrinsic membrane dynamics appear to be largely preserved (Margolis et al., 2008; Mazzoni et al., 2008), suggesting that thresholds and kinetics of direct RGC activation may be relatively stable during degeneration. On the other hand, physiological recordings in animal models of retinal degeneration have uncovered aberrant synaptic inputs to RGCs, which have been shown to underlie rhythmic firing and contribute to elevated spontaneous firing rates (Stasheff and Andrews, 2010; Borowska et al., 2011; Sekirnjak et al., 2011; for review, see Margolis and Detwiler, 2011). The resulting changes in RGC resting membrane state, along with intrinsic elevation of hyperactivity observed in a subset of RGCs (Stasheff and Andrews, 2010; Sekirnjak et al., 2011), may alter the sensitivity of RGCs to electrical stimuli.

Several studies have found that outer retinal degeneration can increase RGC activation thresholds to electrical stimulation; however, the majority of these studies examined indirect activation (Jensen and Rizzo, 2008, 2009, 2011; Ye et al., 2010; Goo et al., 2011; Jensen, 2012), or activation that could not be definitively classified as direct or indirect (Rizzo et al., 2003; Suzuki et al., 2004; O'Hearn et al., 2006; Ye et al., 2008). The studies examining direct RGC response thresholds have had inconsistent results. One study of epiretinal stimulation in a mouse model of rapid degeneration found significantly elevated thresholds, although this elevation appeared to be at least partially due to complications with the dissection of the fragile degenerate retinas (Margalit et al., 2011). Studies investigating rat models of retinal degeneration found similar direct activation thresholds at moderate (Pangratz-Fuehrer et al., 2011) and advanced (Sekirnjak et al., 2009) stages of degeneration, in comparison to healthy retinas. Measurements of activity in the superior colliculus (Chan et al., 2011) and visual cortex (Chen et al., 2006) that were thought to reflect direct RGC activation found significantly elevated thresholds, although activity in these central structures may have required simultaneous activation of multiple RGCs, so the observed threshold elevation may have been a reflection of decreased RGC density (Chan et al., 2011) rather than decreased sensitivity of individual RGCs. It remains to be determined whether the response properties of primate RGCs to direct electrical activation are altered in the course of outer retinal degeneration.

\section{References}

Ahuja AK, Behrend MR, Kuroda M, Humayun MS, Weiland JD (2008) An in vitro model of a retinal prosthesis. IEEE Trans Biomed Eng 55:17441753. CrossRef Medline 
Baylor DA, Nunn BJ, Schnapf JL (1984) The photocurrent, noise and spectral sensitivity of rods of the monkey Macaca fascicularis. J Physiol 357: 575-607. Medline

Baylor DA, Nunn BJ, Schnapf JL (1987) Spectral sensitivity of cones of the monkey Macaca fascicularis. J Physiol 390:145-160. Medline

Beebe X, Rose TL (1988) Charge injection limits of activated iridium oxide electrodes with $0.2 \mathrm{~ms}$ pulses in bicarbonate buffered saline. IEEE Trans Biomed Eng 35:494-495. CrossRef Medline

Behrend MR, Ahuja AK, Humayun MS, Chow RH, Weiland JD (2011) Resolution of the epiretinal prosthesis is not limited by electrode size. IEEE Trans Neural Syst Rehabil Eng 19:436-442. CrossRef Medline

Berson DM (2008) Retinal ganglion cell types and their central projections. In: The senses: a comprehensive reference (Masland R, ed), pp 491-520. Oxford, UK: Elsevier.

Borowska J, Trenholm S, Awatramani GB (2011) An intrinsic neural oscillator in the degenerating mouse retina. J Neurosci 31:5000-5012. CrossRef Medline

Brummer SB, Turner MJ (1977) Electrical stimulation with Pt electrodes: II-estimation of maximum surface redox (theoretical non-gassing) limits. IEEE Trans Biomed Eng 24:440-443. CrossRef Medline

Butterwick A, Vankov A, Huie P, Freyvert Y, Palanker D (2007) Tissue damage by pulsed electrical stimulation. IEEE Trans Biomed Eng 54: 2261-2267. CrossRef Medline

Chan LL, Lee EJ, Humayun MS, Weiland JD (2011) Both electrical stimulation thresholds and SMI-32-immunoreactive retinal ganglion cell density correlate with age in S334ter line 3 rat retina. J Neurophysiol 105:26872697. CrossRef Medline

Chen SJ, Mahadevappa M, Roizenblatt R, Weiland J, Humayun M (2006) Neural responses elicited by electrical stimulation of the retina. Trans Am Ophthalmol Soc 104:252-259. Medline

Chichilnisky EJ (2001) A simple white noise analysis of neuronal light responses. Network 12:199-213. CrossRef Medline

Chichilnisky EJ, Kalmar RS (2002) Functional asymmetries in ON and OFF ganglion cells of primate retina. J Neurosci 22:2737-2747. Medline

Cohen E, Agrawal A, Connors M, Hansen B, Charkhkar H, Pfefer J (2011) Optical coherence tomography imaging of retinal damage in real time under a stimulus electrode. J Neural Eng 8:056017. CrossRef Medline

Cunningham W, Mathieson K, McEwan FA, Blue A, McGeachy R, McLeod JA, Morris-Ellis C, O'Shea V, Smith KM, Litke A, Rahman M (2001) Fabrication of microelectrode arrays for neural measurements from retinal tissue. J Physics 34:2804-2809.

Dacey DM (1993a) The mosaic of midget ganglion cells in the human retina. J Neurosci 13:5334-5355. Medline

Dacey DM (1993b) Morphology of a small-field bistratified ganglion cell type in the macaque and human retina. Vis Neurosci 10:1081-1098. CrossRef Medline

Dacey DM (2004) Origins of perception: retinal ganglion cell diversity and the creation of parallel visual pathways. In: The cognitive neurosciences (Gazzaniga MS, ed), pp 281-301. Cambridge, MA: MIT.

Dacey DM, Peterson BB, Robinson FR, Gamlin PD (2003) Fireworks in the primate retina: in vitro photodynamics reveals diverse LGN-projecting ganglion cell types. Neuron 37:15-27. CrossRef Medline

Drasdo N, Fowler CW (1974) Non-linear projection of the retinal image in a wide-angle schematic eye. Br J Ophthalmol 58:709-714. CrossRef Medline

Field GD, Chichilnisky EJ (2007) Information processing in the primate retina: circuitry and coding. Annu Rev Neurosci 30:1-30. CrossRef Medline

Field GD, Sher A, Gauthier JL, Greschner M, Shlens J, Litke AM, Chichilnisky EJ (2007) Spatial properties and functional organization of small bistratified ganglion cells in primate retina. J Neurosci 27:13261-13272. CrossRef Medline

Fried SI, Hsueh HA, Werblin FS (2006) A method for generating precise temporal patterns of retinal spiking using prosthetic stimulation. J Neurophysiol 95:970-978. Medline

Fried SI, Lasker AC, Desai NJ, Eddington DK, Rizzo JF 3rd (2009) Axonal sodium-channel bands shape the response to electric stimulation in retinal ganglion cells. J Neurophysiol 101:1972-1987. CrossRef Medline

Goo YS, Ye JH, Lee S, Nam Y, Ryu SB, Kim KH (2011) Retinal ganglion cell responses to voltage and current stimulation in wild-type and $\mathrm{rd} 1$ mouse retinas. J Neural Eng 8:035003. CrossRef Medline

Greenberg R (1998) Analysis of electrical stimulation of the vertebrate reti- na-work towards a retinal prosthesis (dissertation). Baltimore MD, John Hopkins University.

Grumet AE (1999) Electric stimulation parameters for an epi-retinal prosthesis (dissertation). Cambridge MA, Massachusetts Institute of Technology.

Hottowy P, Dąbrowski W, Skoczeń A, Wiącek P (2008) An integrated multichannel waveform generator for large-scale spatio-temporal stimulation of neural tissue. Analog Integr Circ Sig Process 55:239-248. CrossRef

Hottowy P, Beggs JM, Chichilnisky EJ, Dąbrowski W, Fiutowski T, Gunning DE, Hobbs J, Jepson L, Kachiguine S, Mathieson K, Rydygier P, Sher A, Skoczeń A, Litke A (2010) 512-electrode MEA system for spatiotemporal distributed stimulation and recording of neural activity. Proceedings of the 7th International Meeting on Substrate-Integrated Microelectrode Arrays, Reutlingen, Germany (Stett, A ed), June 29-July 2, pp 327-330. Stuttgart, Germany: BIOPRO Baden-Wurttemberg.

Hottowy P, Skoczeń A, Gunning DE, Kachiguine S, Mathieson K, Sher A, Wiącek P, Litke AM, Dąbrowski W (2012) Properties and applications of a multichannel integrated circuit for low-artifact, patterned electrical stimulation of neural tissue. J Neural Eng 9:066005. CrossRef Medline

Ishida AT (2003) Retinal ganglion cell excitability. In: The visual neurosciences (Chalupa LM, Werner JS, ed), pp 422-450. Cambridge, MA: MIT.

Jensen RJ (2012) Activation of ganglion cells in wild-type and P23H rat retinas with a small subretinal electrode. Exp Eye Res 99:71-77. CrossRef Medline

Jensen RJ, Rizzo JF 3rd (2008) Activation of retinal ganglion cells in wildtype and rd1 mice through electrical stimulation of the retinal neural network. Vision Res 48:1562-1568. CrossRef Medline

Jensen RJ, Rizzo JF 3rd (2009) Activation of ganglion cells in wild-type and rd1 mouse retinas with monophasic and biphasic current pulses. J Neural Eng 6:035004. CrossRef Medline

Jensen RJ, Rizzo JF 3rd (2011) Effects of GABA receptor antagonists on thresholds of $\mathrm{P} 23 \mathrm{H}$ rat retinal ganglion cells to electrical stimulation of the retina. J Neural Eng 8:035002. CrossRef Medline

Jensen RJ, Rizzo JF 3rd, Ziv OR, Grumet A, Wyatt J (2003) Thresholds for activation of rabbit retinal ganglion cells with an ultrafine, extracellular microelectrode. Invest Ophthalmol Vis Sci 44:3533-3543. CrossRef Medline

Jensen RJ, Ziv OR, Rizzo JF 3rd (2005) Thresholds for activation of rabbit retinal ganglion cells with relatively large, extracellular microelectrodes. Invest Ophthalmol Vis Sci 46:1486-1496. CrossRef Medline

Jones BW, Marc RE (2005) Retinal remodeling during retinal degeneration. Exp Eye Res 81:123-137. CrossRef Medline

Litke AM (1998) The retinal readout system: an application of microstrip detector technology to neurobiology. Nucl Instrum Methods Phys Res A 418:203-209. CrossRef

Litke AM, Bezayiff N, Chichilnisky EJ, Cunningham W, Dąbrowski W, Grillo AA, Grivich M, Grybos P, Hottowy P, Kachiguine S (2004) What does the eye tell the brain?: development of a system for the large-scale recording of retinal output activity. Nucl Sci IEEE Trans 51:1434-1440. CrossRef

Margalit E, Thoreson WB (2006) Inner retinal mechanisms engaged by retinal electrical stimulation. Invest Ophthalmol Vis Sci 47:2606-2612. CrossRef Medline

Margalit E, Babai N, Luo J, Thoreson WB (2011) Inner and outer retinal mechanisms engaged by epiretinal stimulation in normal and rd mice. Vis Neurosci 28:145-154. CrossRef Medline

Margolis DJ, Detwiler PB (2007) Different mechanisms generate maintained activity in ON and OFF retinal ganglion cells. J Neurosci 27:59946005. CrossRef Medline

Margolis DJ, Detwiler PB (2011) Cellular origin of spontaneous ganglion cell spike activity in animal models of retinitis pigmentosa. J Ophthalmol 2011.

Margolis DJ, Newkirk G, Euler T, Detwiler PB (2008) Functional stability of retinal ganglion cells after degeneration-induced changes in synaptic input. J Neurosci 28:6526-6536. CrossRef Medline

Masland RH (2001) The fundamental plan of the retina. Nat Neurosci 4:877-886. CrossRef Medline

Mazzoni F, Novelli E, Strettoi E (2008) Retinal ganglion cells survive and maintain normal dendritic morphology in a mouse model of inherited photoreceptor degeneration. J Neurosci 28:14282-14292. CrossRef Medline

McCreery DB, Agnew WF, Yuen TG, Bullara L (1990) Charge density and 
charge per phase as cofactors in neural injury induced by electrical stimulation. IEEE Trans Biomed Eng 37:996-1001. CrossRef Medline

Medeiros NE, Curcio CA (2001) Preservation of ganglion cell layer neurons in age-related macular degeneration. Invest Ophthalmol Vis Sci 42:795803. Medline

Merrill DR, Bikson M, Jefferys JG (2005) Electrical stimulation of excitable tissue: design of efficacious and safe protocols. J Neurosci Methods 141: 171-198. CrossRef Medline

O'Hearn TM, Sadda SR, Weiland JD, Maia M, Margalit E, Humayun MS (2006) Electrical stimulation in normal and retinal degeneration ( $\mathrm{rd} 1$ ) isolated mouse retina. Vision Res 46:3198-3204. CrossRef Medline

Pangratz-Fuehrer S, Naik N, Palanker D (2011) Selectivity of epiretinal stimulation of retinal ganglion cells can be controlled by pulse width. Soc Neurosci Abstr 37:482.08.

Petrusca D, Grivich MI, Sher A, Field GD, Gauthier JL, Greschner M, Shlens J, Chichilnisky EJ, Litke AM (2007) Identification and characterization of a Y-like primate retinal ganglion cell type. J Neurosci 27:11019-11027. CrossRef Medline

Rattay F, Resatz S (2004) Effective electrode configuration for selective stimulation with inner eye prostheses. IEEE Trans Biomed Eng 51: 1659-1664. CrossRef Medline

Ray A, Lee EJ, Humayun MS, Weiland JD (2011) Continuous electrical stimulation decreases retinal excitability but does not alter retinal morphology. J Neural Eng 8:045003. CrossRef Medline

Rizzo JF 3rd, Wyatt J, Loewenstein J, Kelly S, Shire D (2003) Perceptual efficacy of electrical stimulation of human retina with a microelectrode array during short-term surgical trials. Invest Ophthalmol Vis Sci 44:5362-5369. CrossRef Medline

Rose TL, Robblee LS (1990) Electrical stimulation with Pt electrodes. VIII. Electrochemically safe charge injection limits with $0.2 \mathrm{~ms}$ pulses. IEEE Trans Biomed Eng 37:1118-1120. CrossRef Medline

Santos A, Humayun MS, de Juan E Jr, Greenburg RJ, Marsh MJ, Klock IB, Milam AH (1997) Preservation of the inner retina in retinitis pigmentosa. A morphometric analysis. Arch Ophthalmol 115:511-515. CrossRef Medline

Sekirnjak C, Hottowy P, Sher A, Dabrowski W, Litke AM, Chichilnisky EJ (2006) Electrical stimulation of mammalian retinal ganglion cells with multielectrode arrays. J Neurophysiol 95:3311-3327. CrossRef Medline
Sekirnjak C, Hottowy P, Sher A, Dabrowski W, Litke AM, Chichilnisky EJ (2008) High-resolution electrical stimulation of primate retina for epiretinal implant design. J Neurosci 28:4446-4456. CrossRef Medline

Sekirnjak C, Hulse C, Jepson LH, Hottowy P, Sher A, Dabrowski W, Litke AM, Chichilnisky EJ (2009) Loss of responses to visual but not electrical stimulation in ganglion cells of rats with severe photoreceptor degeneration. J Neurophysiol 102:3260-3269. CrossRef Medline

Sekirnjak C, Jepson LH, Hottowy P, Sher A, Dabrowski W, Litke AM, Chichilnisky EJ (2011) Changes in physiological properties of rat ganglion cells during retinal degeneration. J Neurophysiol 105:25602571. CrossRef Medline

Silveira LC, Perry VH (1991) The topography of magnocellular projecting ganglion cells (M-ganglion cells) in the primate retina. Neuroscience 40: 217-237. CrossRef Medline

Stasheff SF, Andrews MP (2010) A subpopulation of retinal ganglion cells sustains spontaneous hyperactivity through non-synaptic mechanisms in mice with retinal degeneration. ARVO Meeting Abstracts 51:5798.

Suzuki S, Humayun MS, Weiland JD, Chen SJ, Margalit E, Piyathaisere DV, de Juan E Jr (2004) Comparison of electrical stimulation thresholds in normal and retinal degenerated mouse retina. Jpn J Ophthalmol 48:345-349. Medline

Tsai D, Morley JW, Suaning GJ, Lovell NH (2009) Direct activation and temporal response properties of rabbit retinal ganglion cells following subretinal stimulation. J Neurophysiol 102:2982-2993. CrossRef Medline

Weiland JD, Anderson DJ, Humayun MS (2002) In vitro electrical properties for iridium oxide versus titanium nitride stimulating electrodes. IEEE Trans Biomed Eng 49:1574-1579. CrossRef Medline

Weiland JD, Cho AK, Humayun MS (2011) Retinal prostheses: current clinical results and future needs. Ophthalmology 118:2227-2237. CrossRef Medline

Ye JH, Kim KH, Goo YS (2008) Comparison of electrically-evoked ganglion cell responses in normal and degenerate retina. Conf Proc IEEE Eng Med Biol Soc 2008:2465-2468. Medline

Ye JH, Ryu SB, Kim KH, Goo YS (2010) Retinal ganglion cell (RGC) responses to different voltage stimulation parameters in $\mathrm{rd} 1$ mouse retina. Conf Proc IEEE Eng Med Biol Soc 2010:6761-6764. Medline 